THE JOURNAL OF INFECTIOUS DISEASES - VOL. 153, NO. 2 - FEBRUARY 1986

(C) 1986 by The University of Chicago. All rights reserved. $0022-1899 / 86 / 5302-0007 \$ 01.00$

\title{
Ubiquinone-8 Stimulates Phagocytosis in Macrophages by Modulation of the Kinetics of the Fc Receptor
}

\author{
L. H. Block, A. Georgopoulos, D. Biemesderfer, \\ C. Herzog, M. Kashgarian, and V. Sitaramam
}

\begin{abstract}
From the Department of Medicine, University of Basel, Basel, Switzerland; the Chemotherapy Clinic, University of Vienna, Vienna, Austria; the Department of Pathology, Yale University School of Medicine, New Haven, Connecticut; and the National Institute of Nutrition, Hyderabad, India
\end{abstract}

\begin{abstract}
The effect of exogenous ubiquinone-8 (Q8) on IgG- and C3b-mediated phagocytosis of sensitized sheep red blood cells and of opsonized Staphylococcus aureus by macrophages was studied by morphological and quantitative methods. Q8 stimulated the initial events of phagocytosis, that is, attachment and ingestion, in which occupancy of the Fc receptor by $\mathrm{IgG}$ was shown to be of critical significance. The kinetics of competitive inhibition of phagocytosis of opsonized bacteria by macrophages by using Fc fragments suggested the intimate role of the kinetics of the Fc receptor in the initial events of phagocytosis and, further, the modulation of the kinetics of the $\mathrm{Fc}$ receptor by $\mathrm{Q} 8$ as the basis of enhanced phagocytosis by $\mathrm{Q} 8$.
\end{abstract}

Ubiquinones have a defined role in biologic oxidations at the level of mitochondria and plasma membranes. The mechanism of action of ubiquinones in enhancing nonspecific immune mechanisms that leads to complete protection against bacterial infections (both gram negative and gram positive) in experimental animals is not clearly defined. Thus far, major emphasis has been focused on cytostasis, cytolysis, and release of $\mathrm{H}_{2} \mathrm{O}_{2}$ (which are mediated by ubiquinone in phagocytes) as the basis of its bactericidal influence [1-4].

Phagocytosis is primarily a macrotransport phenomenon and occurs through discrete steps of attachment and internalization, a process finally culminating in specific bactericidal events, such as the generation of $\mathrm{H}_{2} \mathrm{O}_{2}$ [5]. The possibility of a prebactericidal level of action of ubiquinones on the phagocyte has been indicated for several reasons: ( () phagocytosis is an energy-requiring process [6]; (2) addition of exogenous ubiquinone stimulates oxidation of NADPH by the plasma membrane [3]; (3) in vivo bacterial clearance from the blood with concomitant sequestration within the liver and spleen was enhanced by administration of ubiquinone-8 (Q8) [1]; and (4) Q8 also stimulated in vivo phagocytosis of opsonized sheep red blood cells by mouse peritoneal macrophages [7].

Received for publication 24 May 1985, and in revised form 21 August 1985.

Please address requests for reprints to Dr. L. H. Block, Department of Medicine, Kantonsspital, CH-4031 Basel, Switzerland.
A systematic evaluation of the role of Q8 in the initial events of attachment and ingestion is important for two reasons. Because these early events are also triggered by $\mathrm{IgG}$ and $\mathrm{C} 3 \mathrm{~b}$, an analysis of such interactions would aid in an understanding of the phagocytic mechanisms, and a clear distinction between internalization and bactericidal events would also aid in the elucidation of the pathophysiology of specific disease states wherein either or both of these events could be suppressed. In this paper we describe systematic morphological and biochemical studies that show that Q8 enhances both attachment and internalization steps of phagocytosis. The overall effect of Q8 was to stimulate the rates of attachment and ingestion, a process that was also synergistic to the triggering action of IgG and C3b. We also report here unique kinetic evidence that exogenous Q8 modulates the apparent affinity of the Fc receptor to its specific ligands, namely, IgG and Fc fragments.

\section{Materials and Methods}

Preparation of mononuclear phagocytes. Buffy coat cells were isolated from individual units of 500 $\mathrm{ml}$ of fresh, human heparinized blood (in FicollHypaque gradients) obtained from healthy donors [8]. After two washes in HBSS (Microbiological Associates, Walkersville, $\mathrm{Md}$ ) at room temperature, the cells were suspended in Eagle's MEM containing 24 $\mathrm{m} M$ HEPES (GIBCO, Grand Island, NY). The viability of the cells was determined by trypan-blue ex- 
clusion and was found to be $>96 \%$. This fraction contained $17.5 \%$ monocytes, $78.5 \%$ lymphocytes, and $4 \%$ granulocytes, as determined by differential cell counting on cell preparation stained with Türk's solution.

For separation of mononuclear phagocytes, cells were incubated in plastic petri dishes $(35-\mathrm{mm}$ diameter; Falcon Plastics, Oxnard, Calif) at a concentration of $1 \times 10^{8}$ cells $/ \mathrm{ml}$ per dish for $1 \mathrm{hr}$ at $37 \mathrm{C}$ in a $5 \% \mathrm{CO}_{2}$ atmosphere. After this incubation period, the nonadhering cells (containing lymphocytes and PMNLs) were decanted and the dishes gently rinsed with warm MEM. The cells from several dishes were pooled, washed (for $10 \mathrm{~min}$ at $400 \mathrm{~g}$ and $4 \mathrm{C}$ ) with MEM, and quantitated by the nonspecific esterase method [9]. The mononuclear phagocyte content of this cell preparation was $87 \%$ $\pm 7.5 \%$. The cell counts were done in triplicate with the aid of a Neubauer chamber. All assays were done within hours after preparation of the cells, which were stored at $0 \mathrm{C}$.

Purification of Q8. Q8 was isolated from the cell walls of Escherichia coli strain $\mathrm{Ol}$ by using highpressure liquid chromatography, as previously described [5]. Lack of contamination of the compound with endotoxin was confirmed both by amoebocyte lysate assay [10] and by analysis for 2-keto-3deoxyoctonate, with appropriate standards [11]. In addition, Q8 was found to be free of pyrogenicity over a wide range of doses $(25-250 \mathrm{mg} / \mathrm{kg})$ when administered to rabbits. The positive control was bacterial endotoxin, purified from Proteus vulgaris, at a dose of $0.03 \mu \mathrm{g}$ in sterile saline. In the pyrogentesting assays, the mean body temperature of rabbits was $37 \mathrm{C} \pm 0.1 \mathrm{C}$, which changed to $37.3 \mathrm{C} \pm$ $0.2 \mathrm{C}$ with Q8 $(n=11 ; P<.05)$ and $37.8 \mathrm{C} \pm 1.2$ $C$ with bacterial endotoxin $(n=9 ; P<.05)$, which caused biphasic fevers. Q8 was used only in a highly reduced state $(90 \%-95 \%)$, which is critical for its activity.

Procedures for preparation of radiolabeled bacteria and sensitization of sheep red blood cells (SRBCS). We inoculated $20 \mathrm{mI}$ of trypticase-soy broth with Staphylococcus aureus strain $502 \mathrm{~A}$, and a $\left[{ }^{14} \mathrm{C}\right]$-I-amino acid mixture $(50 \mu \mathrm{Ci}$; New England Nuclear, Boston, Mass) was added. The culture was incubated overnight at $37 \mathrm{C}$. Bacteria were then heat killed in boiling water for $30 \mathrm{~min}$, centrifuged at 900 $g$ and washed twice with modified HBSS (Microbiological Associates). S. aureus were resuspended in HBSS, and the number of bacteria added to the suspensions was determined by Petroff-Hausser chamber.

For sensitization of SRBCs with antibody to SRBC, SRBCs (Cordis, Miami) were washed twice in a buffer containing $10 \mathrm{~m} M$ EDTA, $5 \mathrm{~m} M 5,5$ diethylbarbituric acid, $140 \mathrm{mM} \mathrm{NaCl}, 55 \mathrm{~m} M$ glucose, and $0.1 \%$ gelatin ( $\mathrm{pH} 7.4)$; resuspended in the same buffer; and adjusted to a concentration of 2 $\times 10^{8}$ cells $/ \mathrm{ml}$. Aliquots of $0.5 \mathrm{ml}$ of this suspension were each mixed with an appropriate amount of $7 \mathrm{~S}$ or $19 \mathrm{~S}$ rabbit antibody to SRBC (Cordis), adjusted to a final volume of $0.7 \mathrm{ml}$, and incubated in polypropylene tubes (Falcon Plastics) for $30 \mathrm{~min}$ at $37 \mathrm{C}$ followed by a second incubation of $30 \mathrm{~min}$ at $0 \mathrm{C}$.

For SRBC sensitization with C3b, the antibodytreated SRBCs (sensitized with IgG and IgM fractions of rabbit antibody to SRBC) were washed twice with a buffer containing $5 \mathrm{mM}$, 5-diethylbarbituric acid, $140 \mathrm{~m} M \mathrm{NaCl}, 55 \mathrm{~m} M$ glucose, $0.1 \%$ gelatin, $0.15 \mathrm{mM} \mathrm{CaCl}$, and $0.5 \mathrm{mM} \mathrm{MgCl}{ }_{2}$ (pH 7.4) followed by sequential addition of purified $\mathrm{Cl}$ through C4 (Cordis), as described by Theofilopoulos et al. [12]. To confirm the presence of antibody and complement on the cell surface, we exposed the antibodyand C3b-coated SRBCs to fluorescein-labeled antisera to IgG and human C3 and subsequently examined them with a fluorescence microscope (Zeiss, Oberkochen, FRG).

Experimental treatment of macrophages and the phagocytic assay. Q8 in dimethylformamide (Sigma, St. Louis) was added to the cultures. The solvent did not exceed $1 \%$ ( $\mathrm{vol} / \mathrm{vol})$. Preliminary in vitro studies with Q8 indicated that the most pronounced effects occurred when Q8 was in the range between $10^{-4} \mathrm{M}$ and $10^{-5} \mathrm{M}$. Therefore, experiments were carried out with Q8 at a final concentration of $10^{-5} \mathrm{M}$. The corresponding controls contained $1 \%$ dimethylformamide alone, which did not cause measurable effects. All experimental materials were added in 100 $\mu \mathrm{l}$ of MEM. Before performance of the phagocytic assays, macrophages were exposed to Q8 for $60 \mathrm{~min}$ at $37 \mathrm{C}$ in an atmosphere of $5 \% \mathrm{CO}_{2}$.

Studies on phagocytosis were performed by adding $100 \mu \mathrm{l}$ of ${ }^{14} \mathrm{C}$-labeled $S$. aureus (containing $2 \times$ $10^{8}$ bacteria) to each monolayer culture $\left(2 \times 10^{7}\right.$ cells $/ \mathrm{ml}$ per dish) and incubating each culture for different time intervals; three plates were used for each time point. Incubation was stopped by pouring off the supernatant, and monolayers were washed four times with warm $N$-ethylmaleimide $(1 \mathrm{mM})$, 
which quenched further endocytic activity. To distinguish between bound and ingested organisms, we added lysostaphin, at a concentration of $10 \mathrm{U} / \mathrm{ml}$, to kill extracellular bacteria [13]. After two washes with $\mathrm{N}$-ethylmaleimide, the cell layers were allowed to dry overnight; then, $1 \mathrm{ml}$ of $0.2 \mathrm{~N} \mathrm{NaOH}$ was added for digestion ( $2 \mathrm{hr}$ at $37 \mathrm{C}$ ). Each suspension was neutralized with $0.4 \mathrm{ml}$ of $3 \%$ acetic acid, and 1 -ml aliquots were removed for counting and added to $10 \mathrm{ml}$ of Quicksziuti $212^{\circledR}$ (Ziusser Analytic, U.K.). For protein measurements, $100-\mu \mathrm{l}$ samples were taken from each culture, and cell protein was determined according to the method of Lowry et al. [14]. Taking into account the specific activity of the radioactivity (cpm per organism), we calculated the number of bacteria phagocytized by the mononuclear phagocytes from the uptake of radioactivity. Phagocytic activity was then expressed as the number of bacteria $\times 10^{3} / \mu \mathrm{g}$ of cell protein. Radioactivity was counted in an Auto Gamma-Scintillation spectrometer (Packard Instrument, Downers Grove, Ill) with an efficiency of $50 \%$. All assays were run in triplicate.

During phagocytosis, the incubation mixtures contained $10 \%$ either freshly prepared or complementinactivated serum (inactivated by incubation at $55 \mathrm{C}$ for $30 \mathrm{~min}$ ). The competition experiments with $\mathrm{Fc}$ fragments were performed in the presence of a subfraction of human gammaglobulin containing only IgG [15].

For assessment of erythrophagocytosis by human mononuclear phagocytes, freshly prepared SRBCs were sensitized as indicated above; washed twice with a buffer containing $10 \mathrm{~m} M$ EDTA, $5 \mathrm{~m} M 5,5$ diethylbarbituric acid, $140 \mathrm{~m} M \mathrm{NaCl}, 55 \mathrm{~m} M$ glucose, and $0.1 \%$ gelatin ( $\mathrm{pH} 7.4$ ); and washed once with MEM. The mononuclear phagocyte:SRBC ration during incubations was 1:10. Erythrophagocytosis was allowed for various time intervals at $37 \mathrm{C}$ in a $5 \% \mathrm{CO}_{2}$ atmosphere and was stopped as described above. The noninternalized SRBCs were lysed by using a $0.83 \%$ ammonium chloride solution. Reliability of the $0.83 \%$ ammonium chloride solution to yield complete lysis of extracellular SRBCs was routinely confirmed by microscopic examination. After one more washing step with MEM, the cover slips were removed, dried, and stained with Wright's stain. Phagocytosis was calculated by counting internalized SRBCs within 500 mononuclear phagocytes [16]. Mononuclear phagocytes were divided into four class intervals that contained zero, one to two, three to four, and five or more SRBCs per cell. Results were expressed by calculating the phagocytic index (PI) as follows: $\mathrm{PI}=\mathrm{Pi} \overline{\mathrm{X}} \mathrm{i} / \mathrm{Pi}$, where Pi equals the number of macrophages in the $i$ th class interval and $\overline{\mathrm{X}} \mathrm{i}$, the average uptake of SRBCs per cell.

Scanning electron microscopy. Electron microscopic studies on the action of Q8 were performed with the use of guinea pig peritoneal macrophages, prepared according to the method of Nathan et al. [17]. The collected macrophages were loaded into capillary tubes by using the method of David and David [18]. One end of the tube was sealed with wax. The capillary tube was then centrifuged for $4 \mathrm{~min}$ at $800 \mathrm{~g}$ and cut at the cell-liquid interphase. The capillary tubes were transferred to migration chambers (Miles Laboratories, Elkhart, Ind), and the sealed ends were fixed on a wax spot. The open end was positioned on either a 4-mm diameter silicon disk or a 4-mm square piece of millipore filter. The macrophages migrated onto the silicon disks or the millipore filters in the presence or absence of Q8 for $18 \mathrm{hr}$ at $37 \mathrm{C}$, after which the monolayers were exposed to the bacteria and SRBCs for different time intervals. The cells were then processed for scanning electron microscopy and transmission electron microscopy, as described previously [7]. Observations represent the average of four independent experiments.

\section{Results}

Morphological studies of the effect of $Q 8$ on the uptake of S. aureus by guinea pig macrophages. The effect of any agent on a primary surface phenomenon such as phagocytosis should first be established in terms of specificity and duration of the response, to rule out the qualitative influence of changes in surface architecture, which is indeed quite complex for a macrophage. The attachment of organisms to a phagocyte was studied with an improved scanning electron microscopic technique recently developed by Biemesderfer et al. [7]; this technique permits a detailed examination for surface changes with little or no disruption of the monolayer. Addition of opsonized $S$. aureus, both to control and Q8-treated macrophages, resulted in extensive ruffling of the plasma membrane as well as lamellipodia formation (figures 1 and 2), in conformity with an earlier report [19]. The only morphological difference noted was that the Q8-treated macrophages exhibited twoto fourfold increases in attachment of bacteria when 


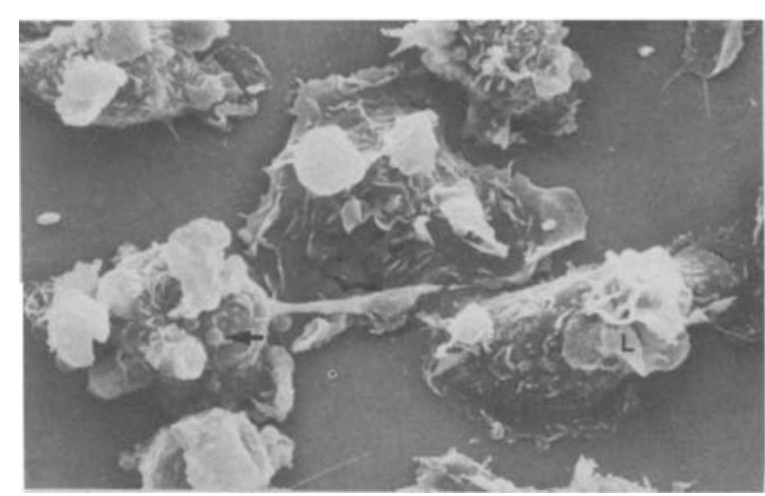

Figure 1. Scanning electron micrograph of control macrophages incubated with opsonized $S$. aureus (arrow) for $5 \mathrm{~min}$. Note the extensive lamellipodia (L) formation $(\times 1,464)$.

compared with controls. This was observed as early as 5-10 min, with a parallel increase in the frequency of engulfment of bacteria. It should be emphasized that this difference was only quantitative; no qualitative differences could be observed on the macrophage surfaces by scanning electron microscopy.

Longer periods of incubation of both control and Q8-treated macrophages (i.e., 4-6 hr) resulted in a number of ultrastructural changes common to both of the groups: the presence of a large number of bacteria as well as reduction in the degree of ruffling, presumably due to sequestration of the plasma membrane within (figure 3, right), which was not seen in the early stages of phagocytosis (figure 3, left); dense clumping of the chromatin; less prominent Golgi apparatus when compared with the earlier stages of phagocytosis; large accumulation of polyribosomes and rough endoplasmic reticulum; and

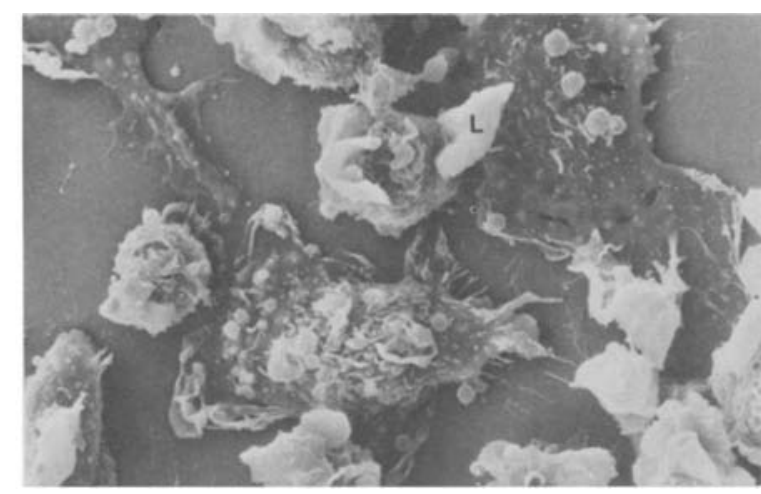

Figure 2. Q8-treated macrophages incubated with $S$. aureus for $5 \mathrm{~min}$. Compare the number of attached particles (arrows) with those in figure 1. L, lamellipodia $(\times 1,464)$.

electron-dense particles containing patches of particles (figures 3, right and 4). The transmission electron microscopic picture at later intervals was consistent with the reported increase in RNA synthesis and a higher rate of delivery of mature ribosomal RNA to the cytoplasm in human monocytes following phagocytosis [20]. These changes are likely to be secondary to the early phagocytic events within the phagocytes, with only quantitative differences between control and Q8-treated cells that cannot be discerned by transmission electron microscopy. For instance, when macrophages were incubated with Q8 for various time intervals, a significant increase $(25 \%-40 \%$ at $2 \mathrm{hr})$ in protein synthesis was noted when compared with controls (data not shown). The fact that the typical morphological and biochemical changes that are characteristic for the "activated macrophage" could not be observed before $12-14 \mathrm{hr}$
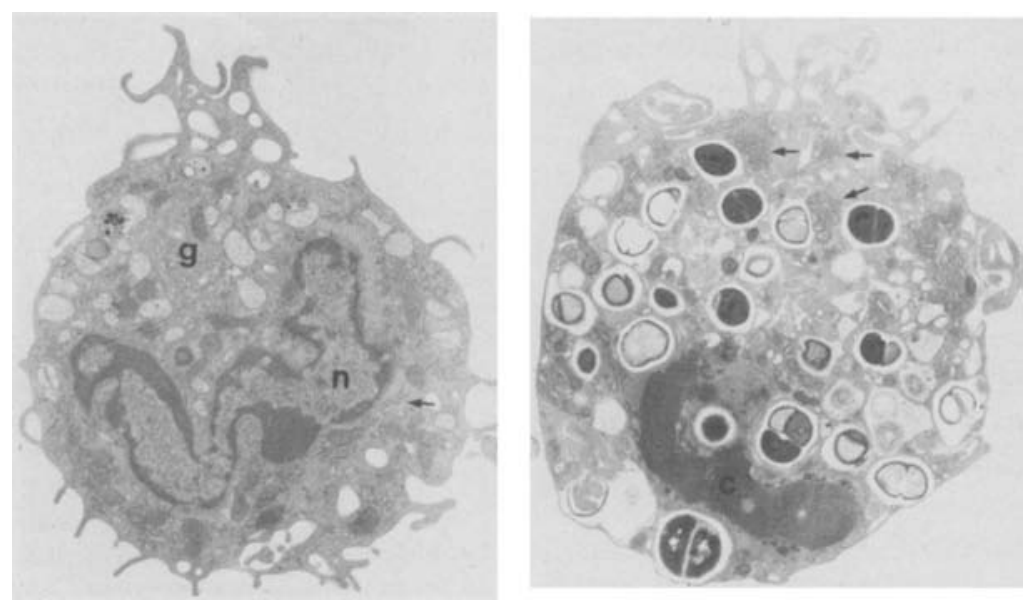

Figure 3. Left, transmission electron micrograph of Q8-treated macrophage incubated for $30 \mathrm{~min}$ with $S$. aureus. Note Golgi apparatus (g), nucleus (n), and rough endoplasmic reticulum (arrow; $\times 5,330$ ). Right, Q8-treated macrophage incubated for $5 \mathrm{hr}$ with $S$. aureus. Note the dense chromatin (c) in the nucleus, the large patches of polyribosomes (arrows) in the cytoplasm, and the smooth plasma membrane $(\times 5,330)$. 
Figure 4. Left, a higher power electron micrograph of the nucleus of a Q8-treated macrophage at a late stage of phagocytosis (4-6 hr). The clumped chromatin (c) and the patches of electron-dense particles (arrow) are evident $(\times 21,320)$. Right, this micrograph demonstrates the accumulation of polyribosomes around the rough endoplasmic reticulum $(\times 30,340)$.
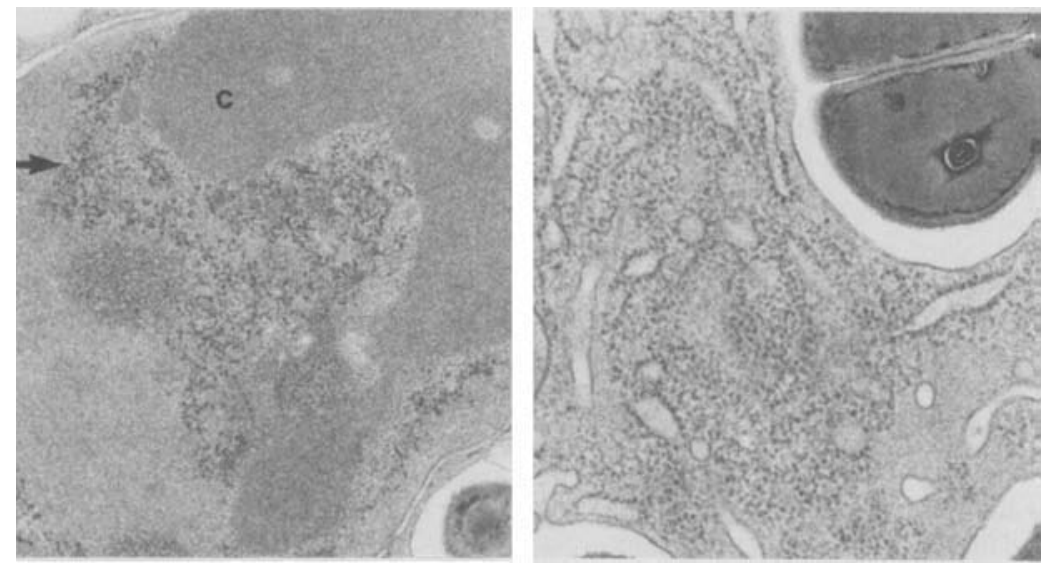

of incubation indicates that the Q8 effect on protein synthesis at $2 \mathrm{hr}$ cannot be attributed to the "activated macrophage."

Because the enhanced attachment and ingestion of bacteria in Q8-treated cells could not be ascribed to either short-term or long-term ultrastructural changes, either at the surface or in the interior, these events were further investigated by detailed quantitative methods.

Effect of $Q 8$ on attachment and ingestion of $S R B C s$ by macrophages. The electron microscopic studies were initially elaborated at a semiquantitative level of light microscopy with regard to the influence of Q8 on attachment and ingestion of sensitized SRBCs by macrophages. We did this in light of our earlier, similar observations based on Q8 treatment in vivo, wherein the mouse peritoneal macrophages were shown to exhibit enhanced attachment to SRBCs following an in vivo administration of Q8 [7]. Both attachment and ingestion were individually scored in each case. It can be seen (table 1) that Q8 per se was marginally ef fective; that IgG but not IgM stimulated both attachment and ingestion, although both of these immunoglobulin fractions were antibodies to SRBCs; that C3b stimulated attachment and ingestion in the presence of both IgG and $\mathrm{IgM}$; and that Q8 potentiated the actions of the immunoglobulins as well as the effect of C3b. The effect of these agents on attachment consistently paralleled that on ingestion, and IgG was the single most effective agent in initiating phagocytosis, since IgM, with or without Q8, was without significant effect unless $\mathrm{C} 3 \mathrm{~b}$ was also present.

These results were consistent with the observations that $(I)$ immunocomplexed IgG increases the phago- cytosis of $S$. aureus by acting as a trigger for endocytosis; (2) the absence of IgM receptors at the surface of the macrophage prevents its binding directly to the membrane in the absence of $\mathrm{C} 3 \mathrm{~b}$; and (3) though $\mathrm{Fc}$ and $\mathrm{C} 3 \mathrm{~b}$ receptors apparently act independently of one another in the binding and phagocytosis of sensitized particles, the two receptors can act synergistically. Occupancy of the receptors seems to be quantitatively of major significance in the stimulation of phagocytosis by Q8. The attachment step per se seems to be of primary significance, since changes

Table 1. The effect of $\mathrm{C} 3 \mathrm{~b}$ and IgG and IgM fractions on attachment and ingestion of SRBCs by mononuclear phagocytes.

\begin{tabular}{|c|c|c|c|c|}
\hline \multirow[b]{2}{*}{$\begin{array}{l}\text { SRBCs } \\
\text { sensitized with }\end{array}$} & \multicolumn{2}{|c|}{ Attachment } & \multicolumn{2}{|c|}{ Ingestion } \\
\hline & $\begin{array}{c}\text { Without } \\
\text { Q8 }\end{array}$ & $\begin{array}{l}\text { With Q8 } \\
\left(10^{-5} M\right)\end{array}$ & $\begin{array}{c}\text { Without } \\
\text { Q8 }\end{array}$ & $\begin{array}{l}\text { With Q8 } \\
\left(10^{-5} M\right)\end{array}$ \\
\hline- & - & $(+)$ & - & $(+)$ \\
\hline $\begin{array}{l}\text { IgG fraction } \\
\text { IgG fraction }\end{array}$ & ++ & ++++ & + & +++ \\
\hline $\begin{array}{l}\text { plus C3b } \\
\text { IgM fraction } \\
\text { IgM fraction }\end{array}$ & $\begin{array}{c}++t \\
-\end{array}$ & $\begin{array}{c}+++t \\
(+)\end{array}$ & $\begin{array}{c}+++ \\
-\end{array}$ & $\begin{array}{c}++++ \\
(+)\end{array}$ \\
\hline plus $\mathrm{C} 3 \mathrm{~b}$ & ++ & +++++ & ++ & ++++ \\
\hline
\end{tabular}

NOTE. SRBCs were sensitized with $\operatorname{IgG}\left(10 \mathrm{ng} / 10^{8} \mathrm{SRBCs}\right)$ or IgM $\left(15 \mu \mathrm{g} / 10^{8} \mathrm{SRBCs}\right)$ in a total volume of $0.7 \mathrm{~mL}$ and then added to monolayers $\left(10^{7} / \mathrm{ml}\right.$ per dish, preincubated for $1 \mathrm{hr}$ with and without $\mathrm{Q} 8$ ) for $60 \mathrm{~min}$ at $37 \mathrm{C}$ in an atmosphere containing $5 \% \mathrm{CO}_{2}$ after which microscopic examination and assessment of the phagocytic index were performed. Five hundred mononuclear phagocytes were scored for each sample: $-=$ no attachment and ingestion, $(+)=0-1,+=1-2,++=3-4$, $t+t=5-6,+t+t=7-8,++t+t=\geqslant 8$ SRBCs at tached to or ingested by mononuclear phagocytes. The data represent the mean of four independent experiments. 


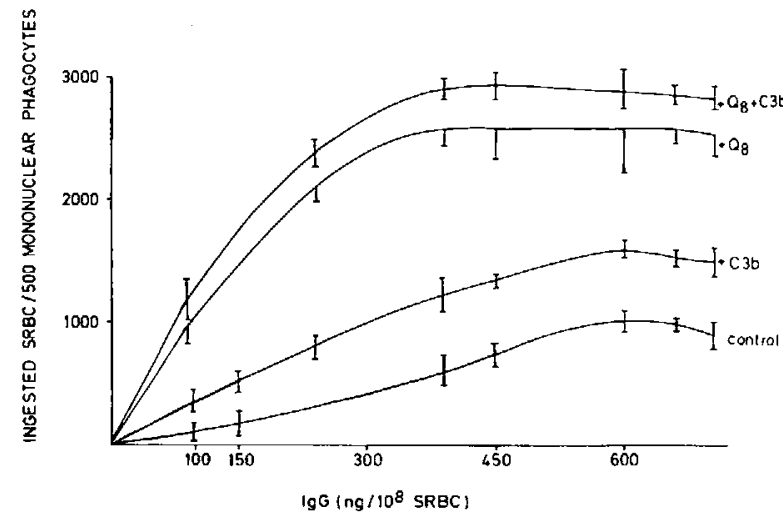

Figure 5. Effect of $\mathrm{Q} 8$ on sensitization profiles for erythrophagocytosis by human mononuclear phagocytes following presensitization with IgM and $\operatorname{IgG}$ antibodies to SRBC and subsequent addition of $\mathrm{IgG}$ antibody to SRBC, C3b, and Q8. Mononuclear phagocytes were sensitized with IgM antibody to SRBC, as described in Materials and Methods. The data represent the mean of four independent experiments \pm SD.

in ingestion always paralleled changes in attachment. In subsequent studies, only ingestion was quantitated because measurement of attachment was less amenable to quantitation, particularly with bacteria.

Because receptor occupancy seemed to be critical to the magnitude of phagocytosis, we varied the IgG in the incubations and quantitated the ingestion of SRBCs as a function of IgG concentration in the medium. Stimulation of phagocytosis by IgG, alone or in the presence of $\mathrm{C} 3 \mathrm{~b}$, exhibited near saturation at $\sim 600 \mathrm{ng}$ of $\mathrm{IgG} / 10^{8} \mathrm{SRBCs}$ (figure 5). On the other hand, the stimulation of phagocytosis by Q8 appeared to be saturated even at a concentration of $\sim 350 \mathrm{ng}$ of $\mathrm{IgG} / 10^{8} \mathrm{SRBCs}$. These results suggested that although $\mathrm{C} 3 \mathrm{~b}$ and IgG could be merely additive, the presence of exogenous Q8 enhanced the apparent affinity of the $\mathrm{Fc}$ receptor to IgG.

Effect of serum and $Q 8$ on bacterial ingestion by macrophages. Phagocytosis of bacteria was markedly stimulated by Q8 in the presence of serum. This threefold stimulation was reflected not only in the magnitude but also in the rate of phagocytosis (figure 6). Heat inactivation of the serum led to significant and proportionate reductions of the rate as well as the magnitude of phagocytosis in both control and Q8-treated macrophages. Treatment of macrophages with heat-inactivated serum did not affect the macrophages adversely, since restoration with fresh serum resulted in restoration of the full phagocytic ac- tivity as well as the stimulatability of phagocytosis by Q8 (figure 6). These results indicated the parallelism between the phagocytosis of SRBCs and $S$. aureus in relation to the action of $\mathrm{Q} 8$.

Effect of $Q 8$ on the inhibitory role of $F c$ fragments on the phagocytosis of $S$. aureus by macrophages. $\mathrm{Fc}$ fragments are known to inhibit phagocytosis of opsonized particles, presumably by competing for the Fc receptors. The enhanced phagocytosis by Q8 could be due to an increased rate of endocytosis with or without an increase in the number of $F c$ receptors on the surface of the macrophage. On the other hand, if the enhanced phagocytosis is mediated by an increased affinity for the $\mathrm{Fc}$ receptor as well, a change in the affinity of the $\mathrm{Fc}$ receptor may be discerned in a competition experiment wherein phagocytosis of opsonized bacteria is quantitated as a function of $\mathrm{Fc}$ fragments in the incubation medium. Data in figure 7 show that phagocytosis of opsonized bacteria (at a constant concentration of IgG) can be inhibited by $\mathrm{Fc}$ fragments such that the $50 \%$ inhibitory concentration $\left(\mathrm{I}_{50}\right)$ was $\sim 35 \mu \mathrm{g} / \mathrm{ml}$ (or approximately two orders of magnitude higher concentration of Fc fragments). Addition of Q8 enhanced not only the magnitude of phagocytosis but also the $\mathrm{I}_{\mathrm{so}}$ of Fc fragments. In fact, stimulation of phagocytosis tended to near saturation at $10^{-7} M \mathrm{Q} 8$, whereas the $\mathrm{I}_{50}$ proportionately increased to $10^{-5} \mathrm{M} \mathrm{Q}$. These results were consistent with the possibility that the addition of exogenous Q8 modified the kinetics of the $\mathrm{Fc}$ receptor, an occurrence facilitating the trig-
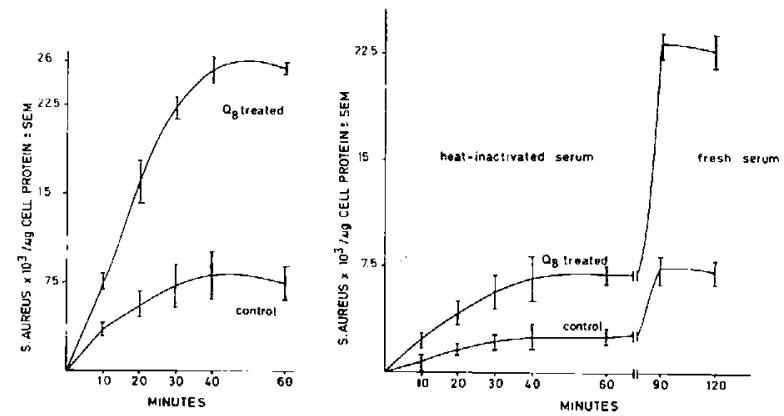

Figure 6. Left, the effect of $\mathrm{Q} 8$ on phagocytosis of ${ }^{14} \mathrm{C}$ labeled $S$. aureus by human mononuclear phagocytes in the presence of fresh serum. The data represent the mean of four independent experiments $\pm \mathrm{SE}$. Right, the ef fect of $\mathrm{Q} 8$ on phagocytosis of ${ }^{14} \mathrm{C}$-labeled $S$. aureus by human mononuclear phagocytes in the presence of heatinactivated serum after reconstitution with fresh serum. the data represent the mean of four independent experiments $\pm \mathrm{SE}$. 


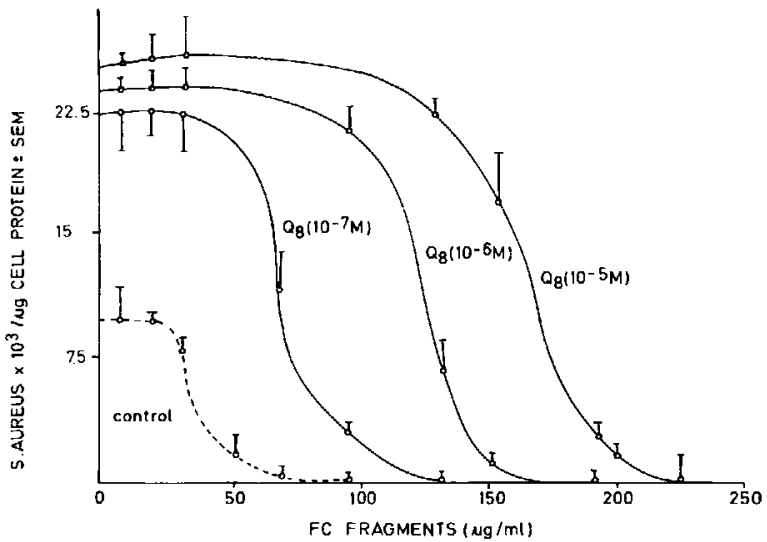

Figure 7. The effect of $\mathrm{Q} 8$ on the IgG-mediated Fc fragment inhibition of phagocytosis by human mononuclear phagocytes. The data represent the mean of five independent experiments \pm SD.

gering effect of IgG on phagocytosis. The quantitative relation between IgG concentration and phagocytosis in these macrophages supported a primarily kinetic interpretation.

\section{Discussion}

The results reported here offer direct evidence for the stimulatory influence of Q8 on the initial events of phagocytosis, namely, attachment and ingestion. The mechanism of action of Q8 does not appear to require any postulate other than its well-authenticated role in electron transport, even with regard to these initial events. Electron transport is diffusion controlled [21]. In a diffusion-coupled reaction that requires collision of membrane components, factors that affect the rate of lateral diffusion must, in turn, affect component interaction [22]. The major parameters in any collison-based reaction mechanism are the concentration of reactants and their diffusion coefficients. Since the diffusion coefficient of a component in the membrane relates to its bulkiness, use of ubiquinones with a shorter chain length, such as Q7 or Q8 as compared with the native ubiquinone Q10, would be consistent with the observed stimulation of respiration. This agrees with a report by Crawford and Schneider [4] who recently identified the role of ubiquinones in microbicidal events. Thus, the shorter ubiquinones (e.g., Q5) were more potent in the stimulation of a respiratory burst than were the higher series analogues.

Occupancy of the $\mathrm{Fc}$ and even the $\mathrm{C} 3 \mathrm{~b}$ receptors appears to be primarily of quantitative (kinetic) rather than qualitative (structural) significance in triggering phagocytosis, an occurrence contributing to the specificity of the microdomain that ultimately constitutes the phagocytic vesicle. The results obtained with SRBCs as well as with $S$. aureus gave a consistent picture in this regard. The phagocytic events of attachment and ingestion essentially behaved consistently as tandem-rate processes, their magnitude being related to the availability of ubiquinones, i.e., the rate of respiration. That the stimulation of various functions in phagocytes by added ubiquinone does not seem to be a nonspecific "tickling" is evidenced in a previous report [4]. First, the stimulation of a respiratory burst is seen in disrupted cells that are no longer responsive to latex particles and phorbol myristate acetate. Second, when disrupted cells are pretreated with Nikkol detergent, the addition of NADPH and ubiquinone still results in oxygen consumption.

The experimental evidence suggests that the kinetics of the $\mathrm{Fc}$ receptor, both in terms of the maximal rate and apparent affinity of the receptor to IgG, varies with the exposure of the macrophages to exogenous Q8. This implies that the enhanced oxidations at the plasma membrane could affect the kinetic properties of the $\mathrm{Fc}$ receptor protein vis-à-vis the phagocytic process. Kinetic evidence related to such macrophenomena is generally suspect due to the inherent complexity of the system, although kinetic interpretations have often yielded illuminating insights in cellular processes such as growth. Precedence for such kinetic evidence has recently been reported, primarily in terms of the perturbations produced in the bilayer as a consequence of respiration [23-25]. (I) Respiration and density of the surface charge were shown to induce variable porosity to osmolytes in the mitochondrial inner membrane (due to dynamic perturbations in the bilayer) that leads to enhanced requirement for isotonicity. (2) Hypoosmotic activation of a variety of membrane-bound enzyme systems (transporters, etc.) was reported, which includes NADPH oxidase of the plasma membrane [26], besides oxidative phosphorylation in mitochondria. (3) Respiration was shown to affect the kinetics of $\beta$-galactoside transport in $E$. coli and dicarboxylate transport in mitochondrial inner membranes. In fact, these studies prompted us to examine the possible alterations in the kinetics of the $\mathrm{Fc}$ receptor. Indeed, addition of Q8 increased not only the maximal rate of phagocytosis, but also the ap- 